\title{
Espiritualidade missionária
}

\author{
Mission Spirituality
}

Luiz Balsan*

Faculdade Vicentina (FAVI), Curitiba, PR, Brasil

\section{Resumo}

Este artigo apresenta uma reflexão sobre os elementos fundamentais da espiritualidade missionária numa perspectiva cristã. Não raro percebe-se na ação pastoral e às vezes até mesmo na reflexão teológica uma compreensão redutiva da espiritualidade entendida apenas como vida interior. Nesse caso, espiritualidade se refere à oração, silêncio e introspecção. Seu sentido, porém, é muito mais amplo! Espiritualidade é vida no Espírito; é a totalidade da vida enquanto animada pela presença e pela ação do Espírito. A partir dessa compreensão, o artigo busca apresentar os elementos essenciais da espiritualidade missionária.

Palavras-chave: Espiritualidade. Espírito Santo. Missão. Missiologia.

*LB: Doutor em Teologia, e-mail: Ibalsan@gmail.com 


\section{Abstract}

This article presents a reflection on the fundamental elements of mission spirituality in Christian perspective. Often one can perceive in the pastoral action and sometimes even in theological reflection a reductive understanding of spirituality, which is understood only as inner life. In this case, spirituality refers to prayer, silence and introspection. Its meaning, however, is much broader. Spirituality is life in the spirit; it's the totality of life, while animated by the presence and action of the Spirit. From this understanding, the article seeks to present essential elements of the missionary spirituality.

Keywords: Spirituality. Holy Spirit. Mission. Missiology.

\section{Introdução}

Espiritualidade é uma palavra que desperta interesse e simpatia na sociedade contemporânea. É valorizada no ambiente religioso e eclesial bem como em ambientes em que não se professa propriamente a fé num ser Transcendente mas que reconhecem nela um elemento ao mesmo tempo natural - enquanto próprio do ser humano - e fundamental na busca de sentido para a condição humana (SOLOMON, 2003).

A reflexão realizada neste artigo se desenvolve na perspectiva da espiritualidade cristã que tem como referência primeira a fé no Deus de Jesus Cristo. O primeiro passo será o de definir a relação entre espiritualidade cristã e inserção no mundo.

No início do terceiro milênio, Casaldáliga (2003, p. 7) principiava sua reflexão sobre a espiritualidade da América Latina, dizendo que espiritualidade é uma palavra infeliz e desmoralizada por causa da compreensão inadequada que teve em boa parte da história do cristianismo, ao ser entendida como algo distante da vida real, desencarnada e como fuga do compromisso histórico. Por influência do platonismo, concebeu-se o espírito como algo que se contrapõe ao corpo e à matéria, vinculando assim a compreensão de que uma pessoa seria tanto mais espiritual quanto mais desprendida do mundo e da matéria. 
Referindo-se também à concepção antropológica platônica, Castillo (2012, p. 11) caminha na mesma direção ao afirmar que espiritualidade é um termo "que encerra sérios perigos". Pela sua íntima relação com a palavra espírito, muitos cristãos, ainda hoje, a entendem como algo "que se opõe à matéria, ao corpo, àquilo que imediatamente é captado pelos olhos e que nós apalpamos, isto é, o mais sensível, o mais próximo, poderíamos inclusive dizer àquilo que é mais nosso". A partir dessa compreensão, muitos concebem a espiritualidade como algo que se contrapõe ao anseio de felicidade e às aspirações humanas mais profundas ${ }^{1}$. Uma oração de benção das famílias em suas casas, que certamente foi usada e continua sendo para a benção de milhões de lares brasileiros, mostra justamente a dificuldade que se tem ainda hoje, em muitos ambientes cristãos, de reconhecer a positividade da inserção e amor ao mundo como elemento constitutivo da espiritualidade cristã. Segundo esta oração, a observância dos mandamentos e a atitude de desincumbir-se dos empenhos no mundo constituem o caminho para a mansão celeste ${ }^{2}$.

A contraposição entre o amor a Deus e o amor ao mundo foi uma das causas do grande desconforto que Teilhard de Chardin (1881-1955) sentiu diante da proposta de espiritualidade apresentada pela Igreja do seu tempo (2010, p. 10-29). Em contraposição à mentalidade de então, a qual pregava a comunhão com Deus através do desprendimento do mundo, ele ensina o caminho inverso: ir a Deus através do mundo.

Deus, naquilo que Ele tem de mais vivo e de mais encarnado, não está distante de nós, fora da esfera tangível, mas Ele nos espera a cada instante na ação, na obra do momento. Ele está, de alguma maneira, na ponta de minha caneta, de minha picareta, de meu pincel, de minha agulha, de meu coração, de meu pensamento. É fazendo progredir, até a sua última perfeição natural, o traço, o golpe, o ponto com o qual estou ocupado, que eu me apoderarei da meta última, à qual tende meu querer profundo (CHARDIN, 2010, p. 31-32).

1 De forma análoga, Aquino Junior (2014, p. 15) fala da necessidade de superar concepções ambíguas, reducionistas e pouco cristãs de espiritualidade.

2 Segue a oração na íntegra: "Deus eterno, que com bondade paterna não deixais de atender às nossas necessidades, derramai a abundância da vossa benção sobre esta família e esta casa, e santificai os seus moradores, com o dom de vossa graça, para que, cumprindo os vossos mandamentos e desincumbindo-se dos encargos do tempo presente, cheguem um dia à mansão celeste para eles preparada. Por Cristo Nosso Senhor" (RITUAL..., 1998, p. 24). 
Teilhard vê a integração entre Deus e a terra como elementos essenciais da espiritualidade cristã (SMULDERS, 1968, p. 229).

\section{Espiritualidade missionária e amor ao mundo}

Diante de propostas que ainda hoje têm dificuldade para integrar o amor a Deus e o amor ao mundo, é preciso lembrar que a espiritualidade cristã tem como referência primeira e fundamental o Deus de Jesus Cristo que, nas palavras do apóstolo João, "amou tanto o mundo que entregou seu Filho único” (Jo 3,16). Em consequência, é preciso afirmar que o caminho que a espiritualidade missionária é chamada a trilhar é o do amor ao mundo e não do distanciamento dele. É esta mística de amor ao mundo que gera e alimenta a missão. Diante do pecado e da rejeição, Deus não se desincumbiu da missão de salvá-lo, mas pelo contrário redobrou o seu amor até chegar à loucura de enviar o seu próprio Filho. O mistério da Encarnação mostra que a espiritualidade missionária cristã é uma espiritualidade de inserção e de encarnação nos mais diversos âmbitos da vida humana e nas mais diversas expressões culturais para que o Evangelho possa cada vez mais se encarnar no mundo, animar e transformar as culturas (PAULO VI, 1975). De forma explícita, Jesus ordena a seus discípulos que se insiram no mundo de modo a serem sal e luz (Mt 5,13-16). As duas metáforas são muito fortes e aludem ao sabor e à iluminação. Transportando a exortação de Jesus para o contexto contemporâneo, onde a produção de conhecimento e as mudanças culturais ocorrem numa velocidade cada vez mais acelerada, torna-se fácil compreender o quanto é exigente a missão confiada por Jesus. Para ser sal e luz é preciso antes de mais nada conhecer profundamente o mundo, suas estruturas e dinâmicas e inserir-se nele com amor, competência, dedicação e criatividade. Fora dessa dinâmica, as palavras de Jesus não alcançarão nenhuma realização.

A espiritualidade missionária precisa, portanto, ser animada ao mesmo tempo pelo amor a Deus e pelo amor ao mundo como duas realidades que se integram e entrelaçam profundamente. 


\section{Espiritualidade como vida no Espírito}

Há uma diferença fundamental na forma de compreender a palavra espírito na cultura grega e hebraica. Ao falar de Deus como espírito, na perspectiva da cultura grega, entende-se que Ele é imaterial. A partir dessa ótica, espiritualidade seria algo contraposto à matéria e ao mundo. Ao falar de Deus como espírito no âmbito da cultura hebraica bíblica, porém, entende-se que Ele é força e energia, Aquele que move à ação. A partir dessa compreensão, a pessoa espiritual é aquela que é animada pela força e pela energia do Espírito Santo.

Codina (2010, p. 24) chama a atenção para o fato que, no Antigo Testamento, o Espírito é compreendido como "uma força misteriosa que, a partir de dentro e de maneira sutil, tudo penetra e ilumina, purifica e santifica, vivifica e dá consistência definitiva”. A partir dessa compreensão, pode-se dizer que a pessoa espiritual é aquela que é penetrada, iluminada e santificada pelo Espírito Santo.

O Novo Testamento tece uma profunda relação entre o Espírito Santo e a pessoa de Jesus. A encarnação do Filho de Deus acontece pela ação do Espírito (Lc 1,35); Ele manifesta-se presente no seu batismo (Jo 1,32); o conduz ao deserto para que, sob a sua assistência, realize sua opção de vida (Mc 1,12-13) e o inunda com sua presença no momento em que, diante de seus conterrâneos, apresenta seu projeto missionário (Lc 4,16-22).

$\mathrm{Na}$ vida dos discípulos, o Espírito é quem conduz à profissão de fé em Jesus Cristo (1Co 12,3). Fundamentado nesta íntima relação entre Jesus e o Espírito, Aquino Junior (2014, p. 24) afirma que a espiritualidade cristã "não é outra coisa senão viver segundo o Espírito de Jesus, isto é, seguir seus passos, viver como ele viveu". De forma muito próxima se pronuncia Estrada (1992, p. 14) ao entender a espiritualidade cristã como vida segundo o espírito de Cristo. Gamarra (1994, p. 36), por sua vez, afirma que "é costume apresentar a espiritualidade como sinônimo de viver sob a ação do Espírito".

O apóstolo Paulo (Rm 8,1-17) contrapõe a vida segundo o Espírito à vida segundo a carne. Não se trata aqui de uma postura dualista, a modo do platonismo, que contrapõe corpo e espírito, mas de uma diferente postura existencial. $\mathrm{O}$ viver segundo a carne, na compreensão de Paulo, indica 
acima de tudo uma vida fechada no horizonte da imanência, isto é, uma atitude existencial de fechamento à ação do Espírito. Em contrapartida, viver segundo o Espírito significa viver orientado "segundo os critérios e as perspectivas de Deus, tal como ficaram encarnadas para sempre na vida e no ensinamento de Jesus" (GALILEA, 1985, p. 75).

A partir da concepção bíblica pode-se falar da ação do Espírito em três dimensões fundamentais. Em primeiro lugar, Ele é apresentado como princípio interior. O profeta Ezequiel identifica na ação interior do Espírito, os sinais da realização das promessas divinas. Ele modifica a pessoa a partir de dentro, do seu núcleo mais profundo, transformando seu coração de pedra num coração de carne, impelindo-a a viver a vida nova expressa através dos mandamentos (Ez 36,26-27). O Novo Testamento apresenta o Espírito como aquele que estabelece, no ser humano, a sua morada $\left(1 C_{0} 3,16\right)$. Sua presença é dinâmica e realiza uma nova condição ontológica e existencial comparada a um novo nascimento, transformando a pessoa em uma nova criatura, capaz de ver o Reino de Deus (Jo 3,4). Pela sua ação dinâmica e contínua, conduz os discípulos de Jesus à compreensão da verdade (Jo 13,16), levando-os a tomar consciência de sua filiação divina $(1 C o$,16) e a professar a sua fé em Jesus, pois "ninguém pode dizer: 'Jesus é o senhor a não ser no Espírito Santo' (1Co 12,3). A partir desta concepção bíblica, a teologia passou a atribuir à ação do Espírito tudo o que leva as pessoas à identificação, à adesão e ao seguimento de Jesus. O caminho de conversão que conduz à fé, o conhecimento de Jesus e o reconhecimento dele como Senhor, o amor por ele, o desejo de segui-lo, e de anunciá-lo: tudo isso se deve à ação do Espírito" (GALILEA, 1985, p. 75).

Na compreensão bíblica e sobretudo neotestamentária há uma outra ação fundamental: a presença do Espírito cria unidade. Neste sentido é interessante a comparação entre duas situações: a construção da torre de Babel, na qual a tradição Javista reconhece uma atitude de orgulho insensato de fechamento a Deus, e o evento de Pentecostes. $\mathrm{Na}$ primeira, mesmo falando uma mesma língua, as pessoas passam a não se entender mais (Gn 11,1-9); em contraposição a isso, falando e agindo sob a ação do Espírito recebido em Pentecostes, as pessoas se entendem mesmo falando línguas diferentes (At 2,1-13). Paulo, por sua 
vez, é enfático ao dizer que o batismo no mesmo e único Espírito une os discípulos a ponto de se tornarem um só corpo (1Co 12,13) onde os carismas são concedidos de forma abundante e plural mas não em função de um protagonismo individual e sim para a edificação da comunidade, critério fundamental do apóstolo na valoração dos carismas (1Co 12,4-11; 14,1-5). Lucas, por sua vez, concebe o ideal da vida cristã numa unidade tal entre os discípulos de Jesus que lhe permite usar a expressão: "um só coração e uma só alma" (At 4,32).

O mesmo Espírito que congrega e cria unidade é o Espírito que envia em missão. Ao receber o batismo no Jordão por obra de João Batista, segundo a narrativa de Lucas "o céu se abriu e o Espírito Santo desceu sobre ele em forma corporal, como pomba" (Lc 3,22). A partir desse momento Jesus inicia a vida pública. Retornando para a Galileia, agindo "com a força do Espírito" torna-se conhecido em toda a região (Lc 4,14) e na sinagoga de Nazaré (Lc 4,16-22), "pleno do Espírito Santo", anuncia seu projeto missionário. Aos seus discípulos, depois da ressurreição, Jesus anuncia que receberão o Espírito Santo e então serão suas testemunhas até os confins da terra (At 1,8). Segundo João (Jo 20,21) no momento em que os envia, da mesma forma como ele fora enviado pelo Pai, lhes diz: "Recebei o Espírito Santo" (Jo 20,21). Assim como o batismo de Jesus inaugura sua vida pública, Pentecostes inaugura a missão da Igreja: "E todos ficaram repletos do Espírito Santo e começaram a falar em outras línguas, conforme o Espírito lhes concedia se exprimissem" (At 2,4). O mesmo Espírito que congrega e cria comunhão é o Espírito que envia à missão.

A espiritualidade missionária é, portanto, a vida vivida na docilidade ao Espírito que, de forma contínua, age no coração humano, transformando-o e conduzindo a pessoa à profissão de fé que, pela ação do mesmo Espírito, deve ser vivida em comunhão com os demais no empenho comunitário e orgânico para que o projeto de salvação de Deus alcance toda a humanidade. O mesmo Espírito que conduz à fé cria comunhão e envia em missão. 


\section{Espiritualidade como seguimento de Jesus Cristo}

A história do cristianismo testemunha a existência de uma grande pluralidade de expressões da espiritualidade cristã. A espiritualidade franciscana, carmelita e inaciana são apenas algumas entre muitas que tomam corpo numa grande pluralidade de manifestações.

Em todas e cada uma, busca-se viver o Evangelho, na fidelidade ao Deus de Jesus Cristo. Ao refletir sobre a diversidade de manifestações da mesma vida cristã, Rahner (1979, p. 15) nota que a realidade subjetiva de cada pessoa e ao mesmo tempo o contexto sociocultural em que ela se encontra são fatores determinantes desta pluralidade. O seguimento de Jesus é vivido de formas diferentes, dependendo das realidades subjetivas de cada um e ao mesmo tempo do ambiente sociocultural em que está inserido.

Por sua vez, Ellacuría (1993, p. 413) ao se referir aos motivos dessa pluralidade, coloca em evidência o fator teológico. O autor afirma que uma única forma de espiritualidade cristã não consegue expressar toda a riqueza do mistério de Deus em Jesus Cristo e nem mesmo o impulso renovador e criador do Espírito Santo. Em segundo lugar fala do fator histórico: por se tratar de uma espiritualidade encarnada na história, a espiritualidade cristã precisa adaptar-se às mais diversas manifestações e expressões socioculturais. Em terceiro lugar, o autor fala da dimensão eclesial: por ser uma realidade orgânica da qual fazem parte diversas opções de vida - sacerdotal, religiosa e laical — os membros da Igreja precisam viver seu seguimento de Jesus Cristo de formas diversas.

Galilea (1985, p. 19) coloca em evidência a dimensão mística, afirmando que a diversidade com que o Espírito Santo nos leva a experimentar a Deus, dá origem a formas diversas de espiritualidade cristã. A partir das narrativas bíblicas, pode-se dizer que desde o início foi assim. Encontrando-se com Jesus as pessoas sentiam-se fascinadas por ele e muitas decidiam por segui-lo, mas de formas diferentes. Uns deixaram tudo e tomaram parte no grupo itinerante que estava sempre com Ele. Outros tornaram-se seus discípulos, mas mantiveram-se na situação de vida em que estavam.

Toda esta diversidade com que se expressa a espiritualidade cristã evidencia uma característica que lhe é própria: a encarnação. A ação 
missionária precisa estar aberta às tantas formas com que o Espírito conduz as pessoas, nas suas mais diversas realidades, ao conhecimento e à profissão de fé em Jesus Cristo e a organizar a partir dela a totalidade de sua vida.

O estudo das expressões mais eminentes da espiritualidade cristã deixa claro que o compromisso missionário é um elemento comum a todas elas. O encontro com Cristo, quando é verdadeiro, leva a pessoa a assumir também seu projeto de vida e salvação para toda a humanidade.

\section{Espiritualidade como paixão pela vida}

Um ícone fundamental da espiritualidade missionária é encontrado no capítulo terceiro do livro do Êxodo, o qual se configura como a experiência fundamental do povo de Israel no Antigo Testamento. Ela será continuamente lembrada e celebrada a ponto de se tornar o alicerce fundamental de sua fé: o Deus que é reconhecido como transcendente é também o Deus próximo, cheio de compaixão que se sensibiliza diante do sofrimento do seu povo: "Eu vi, eu vi a miséria do meu povo que está no Egito. Ouvi o seu clamor por causa dos seus opressores; pois eu conheço as suas angústias. Por isso desci a fim de libertá-lo da mão dos egípcios" (Êx 3,7$)$. O Deus que habita os céus vive uma tal proximidade com seu povo a ponto de ouvir o seu gemido de dor.

Interrogado por Moisés, Deus se apresenta com palavras que normalmente são traduzidas pela expressão: "Eu sou Aquele que é" (Êx3,14). O teólogo contemporâneo Walter Kasper (2015, p. 67), porém, alerta para o fato que tal tradução é criticada pelas ciências bíblicas modernas, enquanto espelha muito mais o pensamento grego do que o hebraico. Enquanto, para o primeiro, o ser é por excelência a essência, para o pensamento hebraico, o ser é existência concreta e eficaz. Segundo o autor, portanto, o nome de Deus pode ser melhor traduzido pela expressão: "Eu sou Aquele que está lá". Esta afirmação é parafraseada por Kasper (2015, p. 66) na forma que segue: "Estou junto a vós e convosco na vossa aflição e no vosso caminho. Ouço e escuto os vossos gritos e lamentações". A partir disso o mesmo autor (2015, p. 67) afirma que no seu próprio nome Deus revela sua identidade mais profunda: "o ser de Deus é existência para o seu povo e com o seu povo". 
A sua compaixão diante desse povo que tem sua vida ameaçada o leva a estabelecer uma relação única com ele: "Tomar-vos-ei por meu povo, e serei o vosso Deus" (Êx 6,7).

Esse amor misericordioso de Deus é expresso por Jesus de forma eminente. Ao revelar o seu Deus, Ele introduz uma mudança radical na mentalidade do seu tempo: o que caracteriza a santidade divina não é a separação do mundo, mas o seu amor compassivo. Em outras palavras, Deus é santo não porque está separado dos impuros, mas porque é compassivo para com todos: "[...] ele faz nascer o seu sol igualmente sobre maus e bons e cair a chuva sobre justos e injustos" (Mt 5,45). A partir disso, Pagola (2012, p. 239) afirma que "A compaixão é o modo de ser de Deus, sua primeira reação diante do ser humano, a primeira coisa que brota de suas entranhas de Pai". Segundo Kasper (2015, p. 90), para o evangelista Lucas, é na misericórdia que Deus revela a sua perfeição. Em consequência, é na mesma misericórdia que se revela o mais alto nível da espiritualidade missionária. Ao apresentar o ideal da vida cristã, Lucas (Lc 6,36) diz: "Sede misericordiosos como o vosso Pai é misericordioso".

Uma das primeiras coisas que salta aos olhos de um observador atento é a diferença entre a atuação de Jesus e a de seu precursor. A atuação de João Batista estava organizada em função de combater o pecado. Sua preocupação primeira era denunciar o pecado das pessoas e convidá-las à conversão, oferecendo-lhes um batismo purificador em função do perdão. Castillo (2015, p. 309) nota que o Batista, ao tentar delinear a figura do messias que estava para chegar, o apresenta com traços de um juiz justiceiro que ameaça os pecadores. A preocupação por excelência do Batista era acabar com o pecado que contaminava o povo e colocava em risco a aliança com Deus. A seu ver, o pecado era o mal que estava desgraçando a vida de todos e provocando a ira de Deus: "O machado já está posto à raiz da árvore e toda árvore que não produzir bom fruto será cortada e lançada ao fogo" (Mt 3,10).

A preocupação de Jesus se orienta em outra direção. Os Evangelhos não $O$ apresentam caminhando pela Galileia em busca de pecadores para convertê-los (PAGOLA, 2012, p. 213). Sua atenção está voltada para as pessoas que viram sua vida minada pelas desgraças que lhes roubaram a dignidade e o gosto de viver. Pessoas que, por motivos muito diversos, 
encontravam-se curvadas pela dor e pelo sofrimento e estavam à beira do caminho ou simplesmente à margem da sociedade (Mc 10,46-52). É a situação desgraçada dessas pessoas que comove suas entranhas. Ele se aproxima dos enfermos, endemoninhados e desorientados a fim de libertá-los para que a vida possa novamente fluir com toda a vitalidade e potencialidade, inerente ao projeto inicial do Criador. Para o evangelista Lucas, Jesus apresenta seu projeto missionário na sinagoga de Nazaré, através da leitura das palavras do profeta Isaías:

O Espírito do Senhor está sobre mim, porque ele me ungiu para evangelizar os pobres; enviou-me para proclamar a remissão aos presos e aos cegos a recuperação da vista, para restituir a liberdade aos oprimidos e para proclamar um ano de graça do Senhor (Lc 4,18-19).

A menção que faz a estas quatro classes de pessoas não tem uma conotação de exclusividade, mas de representatividade. Nos pobres, presos, cegos e oprimidos estão representadas todas as pessoas que de uma forma ou outra sentem sua vida ameaçada ou limitada ${ }^{3}$. São estas situações que mexem com as entranhas de Jesus e despertam nele o mais sublime sentimento da compaixão. É de modo todo particular para elas que Jesus está construindo o seu projeto missionário.

No Evangelho segundo Mateus, esta mesma ideia aparece de forma semelhante. Aos discípulos de João Batista que perguntam a Jesus se era Ele quem devia vir ou se ainda deviam esperar um outro, Jesus evita dar uma resposta afirmativa ou negativa e pede para que contem a João o que eles mesmos estão vendo e ouvindo de seu ministério: "os cegos recuperam a vista, os coxos andam, os leprosos são purificados, os surdos ouvem, os mortos ressuscitam e aos pobres é anunciado o Evangelho" (Lc 7,22). Estas palavras apontam para as obras de Jesus como caminho para se chegar ao coração de sua missão. Diante disso, Kasper (2015, p. 87) conclui: "A solicitude pelos miseráveis e pelos pobres, pelos pequenos e pelos insignificantes de um ponto de vista humano é, deste modo, a

3 Qualquer discurso excludente soa muito estranho diante do plano universal de salvação de Deus. Seria uma contradição o Deus misericordioso excluir qualquer dos seus filhos. É por isso que o centurião romano, que certamente não se enquadra na categoria de pobre do ponto de vista econômico e social, também encontra misericórdia em Jesus (LC 7,1-10). 


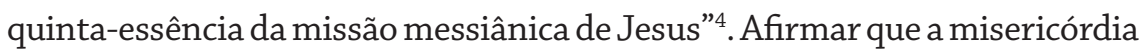
é a quinta-essência da missão messiânica de Jesus comporta, logicamente, afirmar que ela é também a quinta-essência da missão da Igreja.

Kasper (2015, p. 88) nota que o termo "pobres" aqui não se refere apenas àqueles que são pobres do ponto de vista econômico e social, mas se estende a todos os que tem um coração dilacerado, aos desanimados e aos desesperados: àqueles que se apresentam diante de Deus como mendigos.

O coração de Jesus se moveà compaixão diante dos que carregam pesos pesados e por isso sentem-se cansados e oprimidos (Mt 11,28). Sua missão tem o seu núcleo fundamental em duas tarefas expressas pelo evangelista em linguagem narrativa: "Jesus percorria toda a Galileia [...] pregando o evangelho do Reino e curando toda e qualquer doença ou enfermidade do povo" (Mt 4,23). São Marcos (Mc 1,14) introduz a missão de Jesus, dizendo que "Cumpriu-se o tempo e o Reino de Deus está próximo". Nos capítulos seguintes, o evangelista mostra como o Reino se faz presente, através da narração das ações de Jesus que cura os doentes e expulsa os demônios, isto é, vence as forças que destroem a vida dos seres humanos (KASPER, 2015, p. 87). No Evangelho segundo João $(10,10)$, Jesus é apresentado como o bom pastor e o sentido de sua missão é expresso pela frase: "Eu vim para que tenham vida e a tenham em plenitude". Conduzir todos à vida plena é o grande projeto de missão de Jesus de Nazaré.

A partir disso, percebemos a relevância da afirmação de Castillo (2012, p. 38): “a espiritualidade do Evangelho consiste exatamente no fato de que a causa de Deus se funde e se confunde com a causa da vida humana". Na espiritualidade cristã, o amor a Deus e o amor ao próximo aparecem de forma inseparável. Em consequência, não há verdadeiro amor por Cristo sem participar de sua paixão pelo Reino de Deus que compromete o cristão na luta em defesa da vida e da dignidade de todos os filhos de Deus. A espiritualidade missionária, portanto, comporta o estar lá assim como Deus se revelou sempre presente nas situações de dor e sofrimento de seu povo para que a vida possa sempre desabrochar em toda a sua beleza e esplendor.

40 que dizem estes textos programáticos já está implícito na primeira bem-aventurança: “Felizes os pobres em espírito" (Mt 5,3). 


\section{Considerações finais}

Embora, por influências de compreensões alheias ao Evangelho, por longos séculos a espiritualidade cristã tenha sido associada ao desprendimento do mundo, o encontro com o Deus de Jesus Cristo conduz aos caminhos da inserção e amor ao mundo, sob a ação contínua do Espírito. O mistério da Encarnação mostra que a espiritualidade missionária cristã segue o caminho da inserção, da proximidade e da sensibilidade diante dos anseios e clamores concretos de cada grupo humano. O Deus que amou o mundo a ponto de enviar seu próprio Filho para que todos tenham vida plena mostra que a mística missionária inclui, como elemento fundamental, o amor apaixonado pela vida que se expressa no compromisso para que a salvação desejada por Deus chegue a todos os povos e alcance o ser humano na sua integralidade.

\section{Referências}

AQUINO JUNIOR, F. Viver segundo o espírito de Jesus Cristo: Espiritualidade do seguimento. São Paulo: Paulinas, 2014.

BíBLIA de Jerusalém. São Paulo: Paulinas, 1993.

CASALDALIGA, P. Nossa espiritualidade. 3. ed. São Paulo: Paulus, 2003.

CASTILLO, J. M. Espiritualidade para insatisfeitos. São Paulo: Paulus, 2012.

CASTILLO, J. M. La religión de Jesús. Bilbao: Desclée De Brouwer, 2015.

CHARDIN, T. de. O meio divino. Petrópolis: Vozes, 2010.

CODINA, V. "Não extingais o Espírito" (1Ts 5,19): iniciação à pneumatologia. São Paulo: Paulinas, 2010.

ELLACURÍA, I. Espiritualidad del seguimiento. In: FLORISTÁN, J.; TAMAYOACOSTA, J. (Dir.). Conceptos fundamentales del cristianismo. Madrid: Trota, 1993. p. 413-414. 
BALSAN, L.

ESTRADA, J. A. La espiritualidad de los laicos. Madrid: San Pablo, 1992.

GALILEA, S. O caminho da espiritualidade. São Paulo: Paulinas, 1985.

GAMARRA, S. Teología espiritual. Madrid: BAC, 1994.

KASPER, W. A misericórdia: condição fundamental do Evangelho e chave da vida cristã. 2. ed. São Paulo: Loyola, 2015.

PAGOLA, J. A. Jesus: uma aproximação histórica. 5. ed. Petrópolis, Vozes, 2012.

PAULO VI. Evangelii Nuntiandi. São Paulo: Paulinas, 1975.

RAHNER, K. Curso fundamental sobre la fe. Barcelona: Herder, 1979.

RITUAL de bênçãos simplificado. São Paulo: Paulus, 1998.

SMULDERS, P. A visão de Teilhard de Chardin. Petrópolis: Vozes, 1968.

SOLOMON, R. C. Espiritualidade para céticos - Paixão, verdade cósmica e racionalidade no século XXI. Trad. Maria Luiza X. de A. Borges. Rio de Janeiro: Civilização Brasileira, 2003.

Recebido: 30/08/2018

Received: 08/30/2018

Aprovado: 25/10/2018

Approved: 10/25/2018 